\title{
高岭石及其热处理产物的 ${ }^{29} \mathrm{Si},{ }^{27} \mathrm{Al}$ 魔角 旋转核磁共振研究
}

何宏平 胡 澄(1) 郭九臬 张惠芬

(12) 南京大学固体微结构物理实验室,南京 210008; 中国科学院地球化学证究所广州分部,广州 510640)

\section{关链调高岭石、签角旋转核磁共振}

自 80 年代中期, 随着 ${ }^{27} \mathrm{Al},{ }^{29} \mathrm{Si}$ 魔角旋转核磁共振 (MAS NMR) 技术在粘土矿物研究 中的应用, 使人们对粘土矿物受热转变机制有了更深刻的认识. 在高岭石一莫来石反应系列 中, 是否存在 $\mathrm{Al}_{2} \mathrm{O}_{3}$ 和 $\mathrm{SiO}_{2}$ 的分凝及其量的多少, 这是高岭石受热相变机制中一个激烈争论 的问题. Rocha, Klinowski ${ }^{[1]}$, 郭九泉等 ${ }^{[2]}$ 认为, 在高岭石一莫来石反应系列中, 存在有 $\mathrm{Al}_{2} \mathrm{O}$ s 和 $\mathrm{SiO}_{2}$ 的大规模分凝; 而 Chakraborty 等 ${ }^{[3]}$ 认为, 在高岭石向莫来石的转变过程中, 存在有 “高 蛉石 $\rightarrow$ 变高岭石 $\rightarrow \mathrm{Al}-\mathrm{Si}$ 尖晶石 $\rightarrow$ 莫来石”反应系列,它们之间存在着结构上的连续性, $\mathrm{SiO}_{2}$ 和 $\mathrm{Al}_{2} \mathrm{O}_{3}$ 的分疑是次要的. 另外, Brown 等 ${ }^{[4,5]}$ 认为莫来石的形成有两种途径: 一种途径是 由变高岭石直接转变而来; 另一种途径则是由非晶质的 $\mathrm{SiO}_{2}$ 和 $\mathrm{Al}_{2} \mathrm{O}_{3}$ 反应形成. 针对高岭 石的热转变机制问题,我们对晋北高岭石及其热处理产物进行了 ${ }^{29} \mathrm{Si},{ }^{2} \mathrm{Al}$ MAS NMR 研究.

\section{1 实 验}

本文样品采自我国晋北石炭-二叠煤系地层的鱼石层. 我们首先对样品进行了化学 分 析、X 射线衍射分析 (XRD)、红外吸收光谱 (IR) 和电子顺磁共振 (EPR) 研究. 高岭石的 $X$ 射线行射结果见图 1, 其 Hinckley 指数为 1.35 , 化学成分: $\mathrm{SiO}_{2}$ 为 $43.57 \%, \mathrm{Al}_{2} \mathrm{O}_{3}$ 为

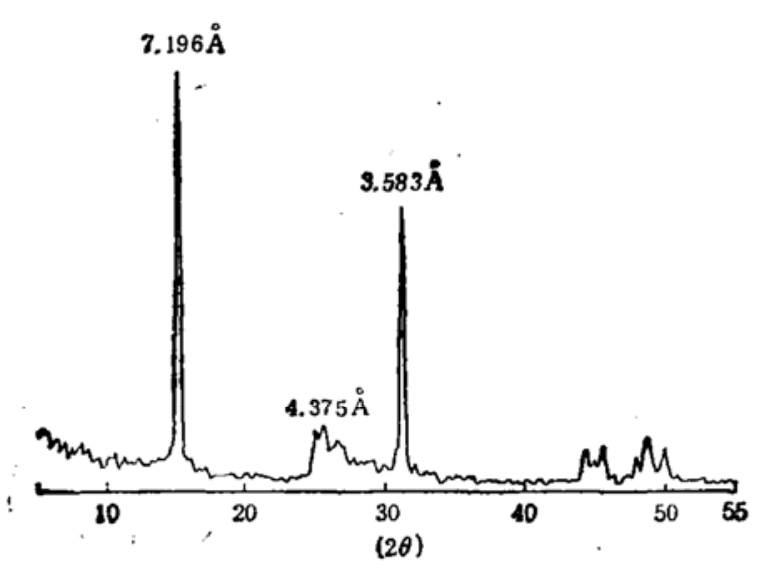

图 1 高岭石的 $\mathbf{X}$ 射线衍射图 $42.20 \%, \mathrm{TiO}_{2}$ 为 $0.42 \%, \mathrm{Fe}_{2} \mathrm{O}_{3}+\mathrm{FeO}$ 为 $0.15 \%, \mathrm{MnO}$ 为 $0.003 \%, \mathrm{CaO}+\mathrm{K}_{2} \mathrm{O}+\mathrm{Na}_{2} \mathrm{O}$ 为 $0.17 \%$. EPR 结喿表明, 其中的 $\mathrm{Fe}$ 主要 是以 $\mathrm{Fe}^{2+}$ 类质同象置换 $\mathrm{Al}^{3+}$ 的形式存在.

样品的热处理是在马弗炉中进行, 先以 相近的升温速率加热到指定 温度、恒温 $1 \mathrm{~h}$ 后, 将样品移至炉外自然冷却. 样品的 ${ }^{29} \mathrm{~S} i$ 和 ${ }^{27}$ AI MAS NMR 谱 (见图 2) 是用带魔角旋 转装置的 Bruker MSL-300 型谱仪在 室温 下记录的, 谐振频率分别为 $59.6 . \mathrm{MHz}$ 和 78.2 $\mathrm{MHz}$, 转子转速 $5 \mathrm{kHz},{ }^{29} \mathrm{Si}$ 和 ${ }^{27} \mathrm{Al}$ 化学位 移的参照物分别为四甲基硅烷（TMS）和三氯化铝溶 液 $\left(\mathrm{AlCl}_{3}\right)$. 样品的红外吸收光谱 用

1992-02-28 收稿, 1992-11-02 收修改稿. 
$\mathrm{KBr}$ 压片法制样, 用 FTIR-170 分光光度计记录。
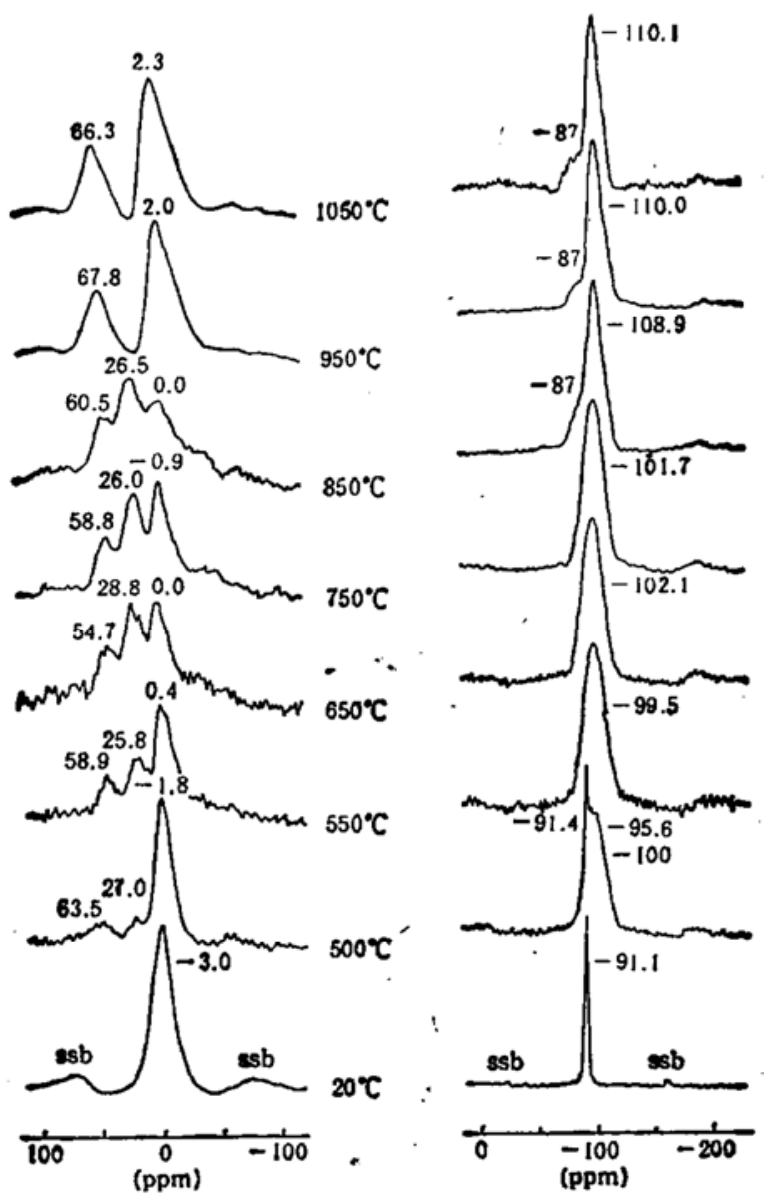

图 2 高岭石及其热处理产物的 ${ }^{27} \mathrm{Al}$ (左)和 ${ }^{29} \mathrm{Si}$ (右)MAS NMS 谱圈 ssb 为旋转边带

\section{2 结果与讨论}

\section{$2.1{ }^{27} \mathrm{Al}$ 橎}

从图 2 可知,在原始高岭石样的 ${ }^{27} \mathrm{Al}$ 谱中, 只在化学位移值为 $-3.0 \mathrm{ppm}$ 的位置出现了一 单峰, 可见在原始高岭石结构中只存在单一的六次配位铝 ( $\mathrm{Al}(\mathrm{VI})$ ). 随着温度升高, 高岭石 中部分羟基的脱失, 结构发生了明显的变化. 大约在 $450-500{ }^{\circ} \mathrm{C}$, 在化学位移值为 $63.5 \mathrm{ppm}$ 和 27.0ppm 位置开始出现四次配位铝 ( $\mathrm{Al}(\mathrm{IV})$ ) 和五次配位铝 ( $\mathrm{Al}(\mathrm{V})$ ) 的谱峰. 温度继续 升高, $\mathrm{Al}(\mathrm{IV})$ 和 $\mathrm{Al}(\mathrm{V})$ 峰的强度明显增强, $\mathrm{Al}(\mathrm{VI})$ 峰强度迅速降低. $800-900^{\circ} \mathrm{C}$ 样品的. ${ }^{n} \mathrm{Al}$ 谱中, $\mathrm{Al}(\mathrm{V})$ 峰强度到达最大值, 明显高于 $\mathrm{Al}(\mathrm{IV})$ 和 $\mathrm{Al}(\mathrm{VI})$ 峰的强度. 当温度升至: $950^{\circ} \mathrm{C}$, 谱峰发生了剧变, $\mathrm{Al}(\mathrm{V})$ 峰全部消失, 在化学位移值为 $67.8 \mathrm{ppm}$ 和 $2.0 \mathrm{ppm}$ 位置出现. 了强度比为 $1: 2.5$ 的新的 $\mathrm{Al}(\mathrm{IV})$ 和 $\mathrm{Al}(\mathrm{VI})$ 峰. 可见在此温度范围, 高岭石的 $\mathrm{Al}-\mathrm{O}(\mathrm{OH})$ 片结构发生了崩塌和重组. 温度升至 $1050^{\circ} \mathrm{C}$, 谱峰无明显变化.

\section{$2.2{ }^{29} \mathrm{Si}$ 谱}

在高岭石及其热处理产物的 ${ }^{29} \mathrm{Si}$ MAS NMR 谱中, 谱峰也呈现规律性的变化. 在原始 高岭石样的 ${ }^{29} \mathrm{Si}$ 谱中, 只在化学位移值为 $-91.1 \mathrm{ppm}$ 位置出现了一单峰, 半高宽为 $2.5 \mathrm{ppm}$, 表明原始高岭石结构中只存在单一的 $\mathrm{SiQ}^{3}$ 结构态 ( $\mathrm{Q}^{n}$ 代表聚合度, $n$ 表示 $\mathrm{SiO}_{4}$ 四面体中 的桥氧数,孤岛状结构的 $n$ 为 1 , 链状结构的 $n$ 为 2 , 其余依次类推). 当温度升至 $450-500{ }^{\circ} \mathrm{C}$ 
左右, 谱峰的重心位置向高场方向(即化学位移负值方向)漂移, 在其宽峰上约-95.6ppm 和 $-100 \mathrm{ppm}$ 位置出现了两个弱峰. 迄今为止, 只有 Rocha, Klinowski ${ }^{[1]}$ 在 1990 年曾报道过 这种谱峰的分裂现象. 在 $550-750^{\circ} \mathrm{C}$ 之间, 谱峰的重心位置稳定在 $-101 \mathrm{ppm}$ 附近, 半高宽达 到最大值, 大约为 $20 \mathrm{ppm}$. 谱峰的化学位移值表明, 此时 $\mathrm{Si}$ 原子的聚合度主要为 $\mathrm{Q}^{3}$, 也即变 高岭石的主体结构仍呈层状结构, 其谱峰的漂移主要是由于结构层内键长、键角的变化所致. 当温度升到 $850^{\circ} \mathrm{C}$, 谱峰重心位置移至 $-108.9 \mathrm{ppm}$, 半高宽明显下降,约为 $15 \mathrm{ppm}$, 与非晶态 $\mathrm{SiO}_{2}$ 或方石英的出现有关. 这表明,在该温度阶段内, $\mathrm{Si}-\mathrm{O}$ 四面体片结构发生了剧变, $\mathrm{Si}$ 的 聚合度由 $\mathrm{Q}^{3}$ 转变成了 $\mathrm{Q}^{4}$. 也即由层状结构转变成了架状结构. 温度继续升至 $1050^{\circ} \mathrm{C}$, 谱峰 重心位置稳定在 $-110.0 \mathrm{ppm}$ 附近, 这是方石英的特征谱盽. 另外, 在 $850^{\circ} \mathrm{C}$ 的 ${ }^{29} \mathrm{Si}$ 谱中, 在 $-87 \mathrm{ppm}$ 位置附近出现了一肩吸收峰, 并且随着温度升高, 谱峰略有增强, 这是莫来石的特征 ${ }^{29} \mathrm{Si}$ 峰.

从 ${ }^{29} \mathrm{Si}$ MAS NMR 谱可知,大规模 $\mathrm{SiO}_{2}$ 的出现大约在 750-850 ${ }^{\circ} \mathrm{C}$ 之间, 也就是说, 此时 高岭石的结构发生了剧变, $\mathrm{Si}$ 原子从 $\mathrm{SiQ}^{3}$ 转变成了 $\mathrm{SiQ}^{4}$. 另外, $-87 \mathrm{ppm}$ 肩峰的出现说明 此时有少量莫来石形成, 但其谱峰远较 $\mathrm{SiO}_{2}$ 的谱峰强度弱. 由此可见, 此时存在于莫来石中 的 $\mathrm{SiO}_{2}$ 的量是很有限的, $\mathrm{SiO}_{2}$ 主要以分凝相形式存在. 据最近几年的资料, 在高岭石向莫 来石的转变过程中, 可能出现四个物相, 即莫来石、方石英、 $\gamma-\mathrm{Al}_{2} \mathrm{O}_{3}$ 和 $\mathrm{Al}-\mathrm{Si}$ 尖晶石. Brown 等 ${ }^{[4,5]}$ 提出, $\mathrm{Al}-\mathrm{Si}$ 尖晶石 ${ }^{29} \mathrm{Si}$ 特征峰的化学位移值大约为 $-79.9 \mathrm{ppm}$, 但在我们的 ${ }^{29} \mathrm{Si}$ 谱中 未见有此峰, 我们可以初步推测该反应体系中没有明显的 $\mathrm{Al}-\mathrm{Si}$ 尖晶石物相存在. 由此, 在 我们的反应体系中可能主要有三个物相: 方石英、莫来石和 $\gamma-\mathrm{Al}_{2} \mathrm{O}_{3}$. 从 ${ }^{27} \mathrm{Al}$ 谱的变化来看, 在 $950{ }^{\circ} \mathrm{C}$ 样品的 ${ }^{27} \mathrm{Al}$ 谱中, 在 $67.8 \mathrm{ppm}$ 和 $2.0 \mathrm{ppm}$ 位置出现了强度比为 $1: 2.5$ 的 $\mathrm{Al}(\mathrm{IV})$ 和 $\mathrm{Al}(\mathrm{VI})$ 峰, 这与 Rocha 等 ${ }^{[1]}, \mathrm{Sanz}$ 等 $^{[6]}$ 的结果是基本一致的. 由于方石英中不含 $\mathrm{Al}$, 不可 能产生 ${ }^{27} \mathrm{Al}$ 信号, 而莫来石的 $\mathrm{Al}(\mathrm{IV})$ 和 $\mathrm{Al}(\mathrm{VI})$ 蜂强度之比大约为 1.3:1 (据 Rocha 等 ${ }^{[1]}$, 郭九帛等 $\left.{ }^{[2]}\right)$,与 $950^{\circ} \mathrm{C}$ 条件下的 ${ }^{27} \mathrm{Al}$ 谱相异甚大, 这说明其中一定叠加了另外一个含 $\mathrm{Al}$ 物相 的 ${ }^{n} \mathrm{Al}$ 信号. 由于我们排除了 $\mathrm{Al}-\mathrm{Si}$ 尖晶石物相存在的可能性。那么这个含 $\mathrm{Al}$ 物相只可 能是 $\gamma-\mathrm{Al}_{2} \mathrm{O}_{3}$. 在 $\gamma-\mathrm{Al}_{2} \mathrm{O}_{3}$ 中, $\mathrm{Al}(\mathrm{IV})$ 和 $\mathrm{Al}(\mathrm{VI})$ 谱峰强度之比大约为 1:3.4 ${ }^{[\mathrm{d}}$, 根据上述 三者的 $\mathrm{Al}(\mathrm{IV})$ 和 $\mathrm{Al}(\mathrm{VI})$ 谱峰强度之比, 初步估算得此时 $\gamma-\mathrm{Al}_{2} \mathrm{O}_{3}$ 的含量大约占含 $\mathrm{Al}$ 物 相的 $71 \%$ 。 上述说明, 在高岭石一莫来石反应系列中存在有大量的 $\mathrm{Al}_{2} \mathrm{O}_{3}$ 和 $\mathrm{SiO}_{2}$ 的分凝, $\mathrm{Al}_{2} \mathrm{O}_{3}$ 和 $\mathrm{SiO}_{2}$ 反应生成莫来石是莫来石的主要形成途径.

另外,高岭石热处理产物的 ${ }^{27} \mathrm{Al}$ MAS NMR 谱表明, 其结构的破坏大约发生在 $950^{\circ} \mathrm{C}$ 附 近; 而 ${ }^{29} \mathrm{Si}$ 谱则表明,其结构破坏发生在 750-850 ${ }^{\circ} \mathrm{C}$ 之间, 两者存在明显的温度差, 这是一个 值得我们深入研究的问题.

致谢南京大学固体微结构物理实验室金通政、韩世莹、䁃云霞老师帮助完成了电子顺 磁共振谱的测定。

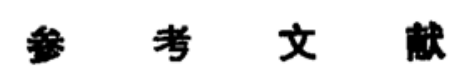

[1] Rocha, J., Klinowski, J., Phys. Chem. Minerals, 1990, 17: 179--182.

[2] 郭九臬等,科学通报, 1991,36(17): 1467-1470.

[ 3] Chakraborty, A. K. ez al., J. Am. Ceram. Soc., 1978, 61(1/2): 90-91.

[4] Brown, I. W. M. et al, J. Am. Ceram. Soc., 1985, 68(6): 298-301.

[5] Mackenzie, K. J. D. et al., J. Am. Ceram. Soc., 1985, 68(6): 293-297.

[6] Sanz, J. et al., J. Am. Ceram. Soc., 1988, 71(10): C418-C421. 